\title{
Frequency and clinical characteristics of rapid-onset fatal and near-fatal asthma
}

\author{
V. Plaza*, J. Serrano*, C. Picado*, J. Sanchis*, on behalf \\ of the High Risk Asthma Research Group
}

Frequency and clinical characteristics of rapid-onset fatal and near-fatal asthma. V. Plaza, J. Serrano, C. Picado, J. Sanchis, on behalf of the High Risk Asthma Research Group. C) ERS Journals Ltd 2002.

ABSTRACT: The onset of fatal and near-fatal asthma attacks can be rapid. The objective of this study was to determine the frequency and clinical characteristics of rapid-onset asthma (ROA) in patients suffering fatal and near-fatal crises.

Two-hundred and twenty patients with fatal or near-fatal attacks were enrolled in a multicentre, prospective study. ROA was defined as a crisis developing in $\leqslant \mathbf{2} \mathrm{h}$. Data on patient and clinical characteristics were collected, and spirometric and allergy studies were performed when the patients were in a stable condition.

Forty-five attacks $(20 \%)$ were ROA and $175(80 \%)$ were slow-onset asthma (SOA). The triggers for SOA and ROA attacks were different, with the ROA group having a significantly lower rate of suspected respiratory infection $(7 \%$ versus $38 \%)$, higher rates of fume/irritant inhalation $(9 \%$ versus $1 \%)$ and a higher intake of nonsteroidal antiinflammatory drugs $(14 \%$ versus $3 \%)$. The ROA group exhibited significantly higher rates of impaired consciousness $(63 \%$ versus $44 \%)$, absence of lung sounds upon admission (68\% versus $42 \%)$, fewer hours of mechanical ventilation (13 h versus 28 h) and fewer days of hospitalization (8 days versus 9.5 days) than the SOA group.

The $20 \%$ frequency of rapid-onset fatal and near-fatal attacks in this study suggests that rapidly developing attacks may not be rare. These findings also support a distinct clinical profile for rapid-onset asthma marked by differences in triggers, severity of exacerbation and clinical course.

Eur Respir J 2002; 19: 846-852.
*Dept of Pneumology, Hospital of the Santa Creu and Sant Pau and "Pneumology and Respiratory Allergy Service, Hospital Clinic, Barcelona, Spain.

Correspondence: V. Plaza, Dept de Pneumologia, Hospital de la Santa Creu i Sant Pau, Sant Antoni M. Claret 167, 08025 Barcelona, Spain. Fax: 34932919266

E-mail: vplaza@hsp.santpau.es

Keywords: Asthma, asthma classification, asthmatic crisis, asthma mortality, fatal asthma, rapid-onset asthma

Received: April 302001

Accepted after revision November 20 2001

This study was supported by a grant of Fundación Española de Neumología y Cirugía Torácica (FEPAR) 1996 and Sociedad Española de Neumología y Cirugía Torácica (SEPAR) 1998.
Early studies of fatal asthma attacks described them as having a single clinical picture [1-3]. WASSERFALLEN et al. [4], however, identified a rapid-onset asthma (ROA) attack developing in $<2$ or $3 \mathrm{~h}$ in contrast to more gradually developing slow-onset asthma (SOA). ROA has been suggested to have a particular clinical course, with rapid impairment and occasionally fatal outcome, although improvement is also rapid when the course is favourable [4]. A classification based on those and other findings has been proposed by PICADO [5]. More neutrophils than eosinophils are known to infiltrate the bronchial submucosa [6] in ROA than in SOA, and ROA is reported to occur in the presence of a higher number of CD8+ T-cells than is seen in stable asthma [7].

Nevertheless, studies supporting the existence of ROA are limited or controversial. Either they rely on isolated clinical observations $[8,9]$, were designed retrospectively [10], or enrolled patients with severe asthma exacerbation (peak expiratory flow (PEF) $<50 \%$ without respiratory acidosis), without including fatal or near-fatal cases $[11,12]$. In most studies, the patient's clinical condition before the near-fatal attack was not documented thoroughly. Their results, therefore, are often contradictory or inconsistent. For example, BARR et al. [11] observed that $14 \%$ of their patients $(125$ of 1,847$)$ suffered an asthma attack established in $<3 \mathrm{~h}$, and that this subgroup had a different pattern of triggers and greater improvement with treatment than patients whose attacks proceeded more gradually. In a smaller study, however, KolBE et al. [13] found that only $8 \%$ of patients with severe asthma exacerbation experienced an onset developing in $<6 \mathrm{~h}$ and reported that no specific clinical course could be discerned for this group. Therefore, in spite of recent papers describing the risk factors for suffering a fatal or near-fatal asthma crisis $[14,15]$, the existence and prevalence of ROA as a distinct clinical event continue to be debated. The confirmation of ROA as a clinically relevant category might have valuable implications for the prevention and treatment of potentially fatal asthma.

The present study was designed to determine the frequency and clinical characteristics of ROA in patients suffering a fatal or near-fatal asthma crisis. To ascertain the character of a true near-fatal asthma crisis, arterial blood gases were also evaluated on admission to the Emergency Room.

\section{Methods}

This prospective, descriptive, hospital-based and multicentre study enrolled asthmatics of both sexes 
aged $\geqslant 5$ yrs, who had experienced a fatal or nearfatal asthma attack and were treated at one of 33 local or referral hospitals participating in the study. Patients fulfilled the American Thoracic Society (ATS) diagnostic criteria for asthma [16]. A fatal or near-fatal crisis was defined as a severe asthma exacerbation with at least one of the following events: 1) respiratory arrest; 2) the need for mechanical ventilation; 3) hypercapnia with arterial carbon dioxide tension $>6.65 \mathrm{kPa}(50 \mathrm{mmHg})$, and/or respiratory acidosis with $\mathrm{pH}<7.30$; or 4$)$ death. Exclusion criteria were concomitant acute serious illness, particularly cardiopathy, and inability to distinguish asthma from chronic obstructive pulmonary disease with bronchial hyperresponsiveness.

ROA was defined as an asthma exacerbation in which a patient in a previously stable condition sought a physician's help within $2 \mathrm{~h}$ of the onset of symptoms. A cut-off time of $2 \mathrm{~h}$ was chosen because studies suggest that different pathogenic mechanisms are involved in fatal asthma crises that become established in $<2 \mathrm{~h}[6,17]$. Stable condition was assumed when the patient reported not having the need to increase the usual dose of anti-asthma medication and not having experienced an increase in the frequency or severity of symptoms prior to the attack for which they sought assistance.

The 33 referral and local hospitals participated voluntarily and were located in different parts of Spain, representing widely differing rural and urban regions. Together, the hospitals serve $\sim 15$ million inhabitants, $\sim 40 \%$ of the population of the country. The Ethics Committee of each hospital approved the study. Informed consent was obtained from patients or their relatives.

Seventy-two variables were identified for data collection, grouped under the following five headings.

\section{Patient characteristics}

Demographic and sociocultural data obtained by interviewing the patient or a relative in case of death or inability to cooperate.

\section{Chronic asthma characteristics}

Morbidity variables, asthma severity before the fatal or near-fatal crisis according to the 1995 guidelines of the Global Initiative for Asthma [18], spirometric values, anti-asthmatic drugs used, type of medical control, presumptive intolerance to nonsteroidal anti-inflammatory drugs (NSAIDs). The information came from the patients' attendant physicians or previous hospital records. If records were unavailable, the patient or a relative was interviewed.

\section{Characteristics of the fatal or near-fatal asthma crisis}

Probable trigger, clinical data, eosinophil and leukocyte counts, arterial blood gases and, when feasible, PEF records obtained by standard procedures. The information was obtained by interviewing the patient or, in case of death or inability to respond, a relative. Clinical data were used to confirm the presence of ROA. Thus, ROA was ruled out if the patient reported the need to increase the usual dose of medication during the days preceding the attack under study, or if the patient reported an increase in the frequency or severity of symptoms during the day and/or at night over the 10 days before seeking emergency care.

The suspicion of acute bronchial infection as the asthma trigger was established when a patient's temperature was $>37^{\circ} \mathrm{C}$ and cough, purulent sputum, or both were present. When signs were accompanied by lung radio-opacity, pneumonia was diagnosed. The patient was questioned about NSAID intake before the asthma crisis and when the answer was affirmative and no other possible concomitant cause was present, NSAID intake was presumed to have triggered the attack. Fume inhalation was considered to have been the trigger when the patient or his family reported contact with toxic vapours or gases (industrial fumes, bleach, sulphur) or potentially irritant smoke (from fire or tobacco) immediately before the attack. Providing other concomitant causes were not present, an allergen was identified as the cause when a patient with a history consistent with allergy was reported to have had recent contact with an allergen for which they also had a positive skin-prick test or specific immunoglobulin (Ig)-E test. Psychosocial stress was considered the trigger when intense emotional situations were reported to have occurred before the attack.

\section{Course of the fatal or near-fatal crisis}

The course of the crisis while the patient was inside the hospital, including the possible need for mechanical ventilation, complications or eventual death. The information was recorded prospectively on each patient's hospital chart.

\section{Studies performed in stable condition}

Tests were conducted after hospital discharge and while a patient was receiving $5-15 \mathrm{mg}$ oral prednisone daily. The tests used were: spirometry before and after salbutamol inhalation, according to ATS recommendations [19]; skin-prick test, according to standard procedure [20] (for Dermatophagoides pteronyssinus, grass and tree pollens, Parietaria judaica, cat and dog dander, soybean dust, and Alternaria spp.); enzyme-linked immunosorbent assay (ELISA; Unicap Pharmacia, Upsala, Sweden) for determination of total IgE and specific IgE serum levels (for soybean dust and Alternaria spp.). Results of the skin-prick test were considered positive when weal diameter was $>3 \mathrm{~mm}$. The information under this heading was obtained in follow-up visits scheduled after hospital release. 
All data collected were sent to the coordinating centre and systematically checked by one of the investigators (J. Serrano). Crisis duration was carefully noted for each case by two investigators (J. Serrano and V. Plaza). Additional patient information was requested from the attending physician when doubts arose. A patient was excluded from the final analysis if information was incomplete. Information was entered into a database and then double checked.

A descriptive analysis of the sample was made using all variables. Data were expressed as percentages or mean \pm SD. For data with a non-Gaussian distribution (assessed by Kolmogorov-Smirnov test), medians were used for analysis. Results for ROA and SOA patients were compared using a Chi-squared test for qualitative variables and either a t-test or MannWhitney U-test for quantitative variables, depending on their distribution. Risk of developing a ROA attack was estimated by multiple logistic regression analysis of the variables that had been found to be significantly different between ROA and SOA patients in the bivariate analysis. A p-value $<0.05$ was considered significant.

\section{Results}

Between April 1997-March 1999, 251 candidate cases were treated at the participating hospitals. Twelve patients did not fulfil the inclusion criteria and were excluded. Three other excluded cases corresponded to second near-fatal episodes in patients who had already been enrolled. Another 13 patients were discarded because the crisis onset time could not be established clearly. Three patients $<5$ yrs of age were also excluded. Therefore, the number of patients included in the final analysis was $220,20 \%$ (45) of whom met the ROA criteria and $80 \%$ (175) met the SOA criteria.

Table 1 shows patient and chronic asthma characteristics. No significant differences in ROA and SOA patient characteristics were observed. Likewise, no differences were observed in the number of relatives with asthma, smoking habits, years with asthma, percentage of moderate or severe asthma or asthmarelated morbidity. However, ROA patients tended to report presumptive NSAID intolerance as a trigger for asthma more often than SOA patients, a difference that was at the limit of statistical significance $(p=0.051)$. Only $44 \%$ of patients in the sample were under a physician's regular care. No differences were observed in use of anti-asthmatic drugs, for which ROA and SOA patients had similar use rates and dosages of inhaled or oral steroids.

Thirty-eight per cent of the 220 patients were smokers or exsmokers when the fatal or near-fatal attack occurred. However, only $33(15 \%)$ of the 126 patients $>50$ yrs of age were smokers or exsmokers, and only $13(6 \%)$ of the 33 had been diagnosed with asthma after age 35 yrs.

More fatal or near-fatal asthma attacks were seen during winter and spring combined $(60 \%)$ than in summer and autumn combined (40\%; $\mathrm{p}=0.005)$. Although a large percentage of ROA cases occurred in spring, as illustrated in figure 1 , no significant differences between the seasonal distribution of ROA and SOA were observed.

Table 1. - Patient and chronic asthma characteristics before a fatal or near-fatal attack according to rapidity of onset

Rapid-onset asthma $(\leqslant 2$ h) Slow-onset asthma $(>2$ h) $\quad$ p-value

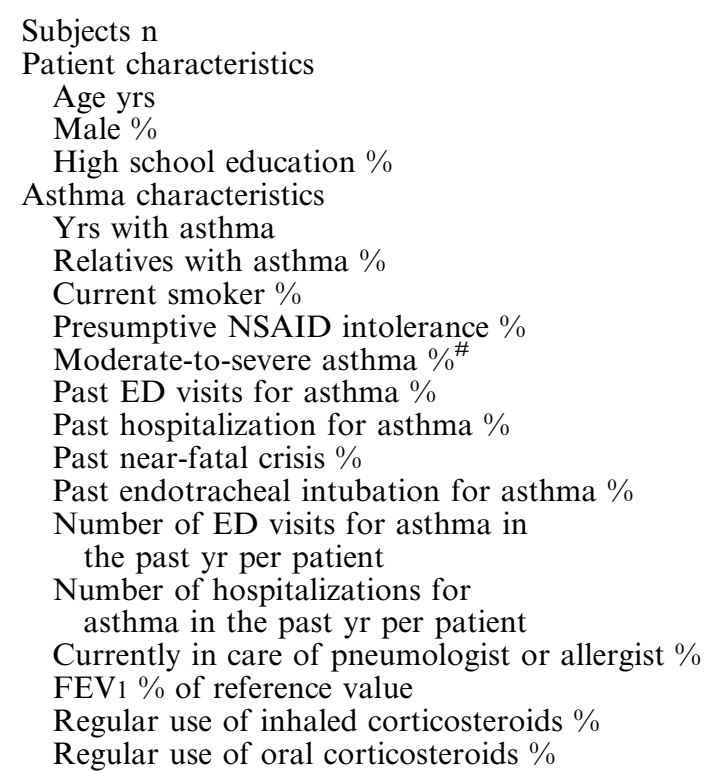

\section{5}

$48 \pm 21$
51
30

$17 \pm 11$
48
18
26
89
93
59
32
9
$1.1 \pm 1.5$


$0.6 \pm 1.2$
48
$73 \pm 22$
60
21

\section{5}

\begin{tabular}{cc}
$50 \pm 21$ & NS \\
37 & NS \\
23 & NS \\
$21 \pm 15$ & NS \\
53 & NS \\
20 & NS \\
12 & 0.051 \\
94 & NS \\
95 & NS \\
61 & NS \\
34 & NS \\
15 & NS \\
$1.2 \pm 1.8$ & NS \\
& \\
& \\
$0.56 \pm 1.1$ & NS \\
58 & NS \\
$74 \pm 25$ & NS \\
57 & NS \\
25 & NS \\
\hline
\end{tabular}

Data are presented as mean \pm SD or percentages. NSAID: nonsteroidal anti-inflammatory drug; ED: emergency department; FEV1: forced expiratory volume in one second; NS: nonsignificant. "\#: Classification of the Global Initiative for Asthma (GINS) of 1995 [18]. 


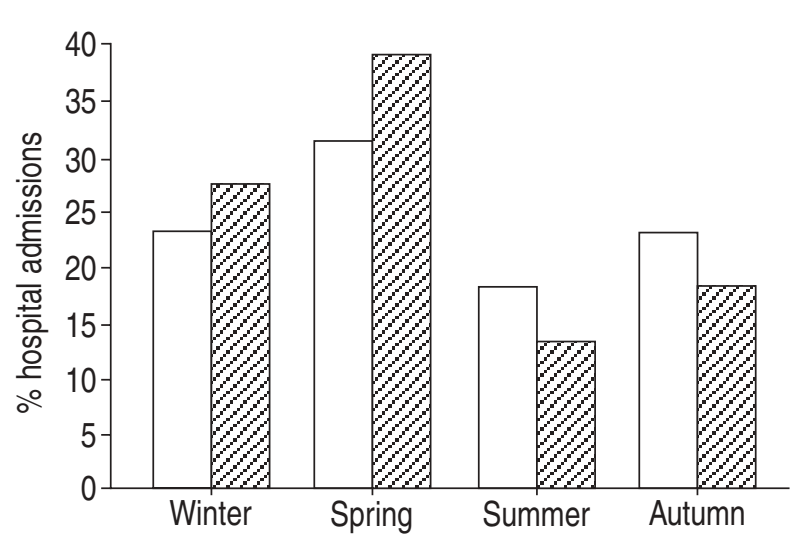

Fig. 1.-Seasonal distribution of cases of fatal or near-fatal asthma, by percentages of cases experiencing rapid- $(\leqslant 2 \mathrm{~h} ; \mathbb{Z})$ or slow- $(>2 \mathrm{~h} ; \square)$ onset asthma.

Table 2 displays triggers, clinical data and course of the fatal and near-fatal asthma attacks. Triggers could be established or suspected in approximately one-half of the cases. In 11 patients $(5 \%)$, NSAID intake was the cause of the fatal or near-fatal asthma attack, six $(14 \%)$ in ROA and five $(3 \%)$ in SOA groups. The NSAIDs identified were aspirin (four cases), diclofenac (two), dexketoprofen (two), naproxen (two), and ketorolac (one). No patient in this study developed signs suggestive of anaphylactic shock. In all patients, signs were consistent with a diagnosis of severe asthma exacerbation. In this study, allergen inhalation was the evident cause of asthma exacerbation in only four cases. PEF was recorded on admission for only $18 \%$ of the patients, probably reflecting the severity of the asthma attacks under study. The most frequently recorded severe complications reported (in 66 patients) were pneumothorax/ pneumomediastinum (nine patients), cardiac arrhythmias (eight), pneumonia (seven), atelectasis (seven), myopathy (seven) and sepsis (six). Infrequent complications were, diabetic acidosis, crisis of high blood pressure, psychotic crisis, gastrointestinal bleeding, glottic oedema, transaminase elevation, oral mycosis, urine infection, cerebrovascular accident and death. Patients came to the hospital by ambulance $(52 \%)$ or private vehicle $(29 \%)$.

Table 3 shows the results of studies performed in stable clinical condition, distributed by rapidity of onset. Such studies were not performed in 15 cases due to death or to cerebral anoxia, and in 24 patients who did not return for follow-up or because a given test was not available at a specific hospital (i.e. specific IgE analysis). Sensitization to an allergen was verified in $58 \%$ of the patients, with sensitization to $D$. pteronyssinus being the most frequent $(35 \%)$, followed by grass pollen $(22 \%)$, dog $(18 \%)$ or cat $(13 \%)$ dander, Alternaria spp. $(9 \%)$ and soybean dust $(4 \%)$.

Multiple logistic regression analysis for risk of suffering a fatal or near-fatal ROA attack identified the following variables to have the greatest weight: absence of lung sounds (odds ratio (OR) 3.604;

Table 2. - Characteristics of fatal and near-fatal asthma attacks by rapidity of onset

\begin{tabular}{|c|c|c|c|}
\hline & $\begin{array}{l}\text { Rapid-onset } \\
\text { asthma }(\leqslant 2 \mathrm{~h})\end{array}$ & $\begin{array}{c}\text { Slow-onset } \\
\text { asthma }(>2 \mathrm{~h})\end{array}$ & p-value \\
\hline Subjects $\mathrm{n}$ & 45 & 175 & \\
\hline \multicolumn{4}{|l|}{ Trigger suspected } \\
\hline Unknown \% & 51 & 47 & NS \\
\hline Respiratory infection $\%$ & 7 & 38 & $* * *$ \\
\hline NSAID intake $\%$ & 14 & 3 & 0.009 \\
\hline Fume inhalation $\%$ & 9 & 1 & 0.003 \\
\hline Psychosocial stress \% & 5 & 2 & NS \\
\hline \multicolumn{4}{|l|}{ Clinical data } \\
\hline Respiratory arrest \% & 43 & 29 & 0.062 \\
\hline Impaired consciousness level $\%$ & 63 & 44 & 0.026 \\
\hline Absence of lung sounds \% & 68 & 42 & 0.047 \\
\hline Tracheal intubation required $\%$ & 56 & 48 & NS \\
\hline Respiratory rate per min & $34 \pm 8$ & $22 \pm 10$ & NS \\
\hline Heart rate per min & $113 \pm 21$ & $117 \pm 21$ & NS \\
\hline $\mathrm{pH}$ & $7.13 \pm 0.15$ & $7.18 \pm 0.16$ & 0.051 \\
\hline$P \mathrm{a}, \mathrm{CO}_{2} \mathrm{kPa}$ & $9.71 \pm 3.86$ & $9.31 \pm 3.99$ & NS \\
\hline Eosinophil count cells $\times 10^{6} \cdot \mathrm{L}^{-1}$ & $459 \pm 413$ & $537 \pm 927$ & NS \\
\hline Leukocyte count cells $\times 10^{6} \cdot \mathrm{L}^{-1}$ & $14.680 \pm 5.046$ & $14.840 \pm 6.374$ & NS \\
\hline \multicolumn{4}{|l|}{ Course } \\
\hline Total dose of systemic steroids in first $24 \mathrm{~h} \mathrm{mg}$ & $263 \pm 301$ & $194 \pm 114$ & 0.020 \\
\hline Days in hospital & $8(6)$ & $9.5(7.7)$ & 0.031 \\
\hline Days in ICU & $1(2.7)$ & $2(4)$ & 0.079 \\
\hline Hours under mechanical ventilation & $13(37)$ & $28(67)$ & 0.005 \\
\hline Death \% & 2.2 & 5.7 & NS \\
\hline Severe neurological sequelae $\%$ & 2.2 & 1.7 & NS \\
\hline Other major consequences $\%$ & 22 & 31 & NS \\
\hline
\end{tabular}

Data are presented as medians (interquartile-range), means \pm SD or as percentages. NSAID: nonsteroidal anti-inflammatory drugs; $P$ a, $\mathrm{CO}_{2}$ : arterial carbon dioxide tension; ICU: intensive care unit; NS: nonsignificant. ***: $\mathrm{p}<0.001$. 
Table 3. - Follow-up studies performed after near-fatal attacks while patients were in stable clinical condition and receiving $<10 \mathrm{mg} \cdot$ day $^{-1}$ of oral prednisone

\begin{tabular}{|c|c|c|c|c|c|}
\hline & $\begin{array}{c}\text { Rapid-onset } \\
\text { asthma }(\leqslant 2 \mathrm{~h})\end{array}$ & $\mathrm{n}^{\top}$ & $\begin{array}{c}\text { Slow-onset } \\
\text { asthma }(>2 \mathrm{~h})\end{array}$ & $\mathrm{n}^{\top}$ & p-value \\
\hline Subject $\mathrm{n}$ & 45 & & 175 & & \\
\hline \multicolumn{6}{|l|}{ Immunological studies } \\
\hline Eosinophil counts cells $\times 10^{6} \cdot \mathrm{L}^{-1}$ & $223 \pm 275$ & & $174 \pm 259$ & 121 & NS \\
\hline Total IgE IU $\cdot \mathrm{mL}^{-1}$ & $267 \pm 268$ & 28 & $340 \pm 579$ & 116 & NS \\
\hline Positive skin-prick test ${ }^{\#}$ & 56 & 39 & 59 & 141 & NS \\
\hline Positive prick test and/or IgE to soybean dust \% & 4 & 39 & 7 & 142 & NS \\
\hline Positive prick test and/or IgE to Alternaria spp. $\%$ & 15 & 39 & 9 & 142 & NS \\
\hline \multicolumn{6}{|l|}{ Spirometry } \\
\hline FEV $1 \%$ of reference value & $73 \pm 25$ & 36 & $75 \pm 23$ & 146 & NS \\
\hline$\triangle \mathrm{FEV}_{1}$ postBD $\%$ & $10.8 \pm 12.7$ & 29 & $8.8 \pm 8.5$ & 132 & NS \\
\hline
\end{tabular}

Data presented as percentages or median \pm SD unless otherwise stated. IgE: Immunoglobulin-E; FEV1: forced expiratory volume in one second; $\triangle \mathrm{FEV} 1$ postBD: $\%$ of FEV1 increase after inhaling salbutamol; NS: nonsignificant. ${ }^{\#}$ : to at least one of the common allergens tested; ": number of patients in whom the study could be performed.

$\mathrm{p}=0.050)$ and lack of suspicion of respiratory infection as the trigger (OR 0.036; $\mathrm{p}=0.018)$.

\section{Discussion}

To the authors' knowledge this is the first prospective study to determine the frequency of rapid-onset fatal and near-fatal asthma and to distinguish the clinical characteristics of this entity. It was found that ROA accounted for approximately one-fifth of all the fatal and near-fatal crises studied. This frequency was higher than the rates of $8 \%$ [13] and $11 \%$ [12] reported for series with less severe cases of asthma exacerbation, but lower than the rates of $29 \%$, observed in a series of intubated patients [10], and $58 \%$, in a study of patients who died due to asthma crises [21]. These data also confirmed that ROA is characterized by greater severity in course of attack, as reported by KoLBE et al. [13], although faster improvement was also observed with treatment, and a different pattern of triggers, as found by BARR et al. [11]. Specifically, suspected respiratory infection was a trigger less often, whereas NSAID intake and gas inhalation were more frequent in ROA than in SOA patients. Together with previous observations [11, 12], these results support the suggestion of PICADO [5] that severe asthma exacerbations may be classfied according to rapidity of onset.

ROA was associated with greater severity of fatal or near-fatal crisis in this study but not with greater severity of chronic disease prior to the attack. In ROA patients, more instances of ominous clinical signs were recorded (lower level of consciousness, absence of lung sounds and greater need for intravenous steroids during the first $24 \mathrm{~h}$ of admission). KolBE et al. [13] also reported features of clinical course and treatment requirements indicative of greater disease severity in ROA patients, specifically, a greater need for mechanical ventilation, more instances of respiratory arrest and more intense gas exchange derangement. In general, these findings are close to those of BARR et al. [11] and of RODRIGO and Rodrigo [12], but differ in part from those of
Kolbe et al. [13], for whom the ROA group made up only $8 \%$ of the series and recovery was slower. However, such discrepancies may have been caused by the inclusion of patients with both severe and less severe asthma attacks by KolBE et al. [13] or to their use of a cut-off point of $6 \mathrm{~h}$ for ROA, whereas most authors fix a cut-off of $2-3 \mathrm{~h}$.

The only difference between ROA and SOA patients with regard to history of chronic asthma was a greater tendency (with a borderline significance) for self-reported suspicion of NSAID intolerance. Taken together with a significantly higher report of NSAID intake prior to the attack by the ROA patients studied (14\% of ROA patients versus $3 \%$ of SOA patients), this seems to support the recommendation that asthmatics avoid NSAID use. However, the clinical signs and causes of the attacks in those patients indicated that a systemic reaction was not implicated, which is to say that the events were true cases of severe, sudden asthma exacerbation, rather than IgE-dependent anaphylactic shock. Conclusions would be premature, however. While these data are consistent with the association of fatal and near-fatal asthma and NSAID use reported by other series in Spain [22] and Japan [23], they are inconsistent with reports from North America [11] and New Zealand [13] of no such association. No explanation can be offered for such geographical differences, although it might be speculated that they are related to differences in patient education or in ease of nonprescription access to potent analgesics containing NSAIDs.

As depicted in table 2, ROA and SOA patients showed significant differences regarding the number of instances of suspected respiratory infections, NSAID intake and fume inhalation as triggers. Although rhinovirus has recently been invoked as a stimulus precipitating ROA [24], these findings do not support that hypothesis. As seen in the studies of BARR et al. [11] and WoodrufF et al. [25], fewer signs of infection in ROA patients were observed in this study, and it can be argued that infection may precipitate more SOA than ROA crises because of the time needed for pathogens to multiply and cause the airway lesions that trigger a crisis. Testing such a hypothesis, 
however, would require additional, specifically designed studies.

Although certain allergens, namely Alternaria spp. [4] or soybean dust [26], have been reported to have precipitated ROA epidemics, allergen inhalation was the evident cause of asthma exacerbation in only four cases in this study and differences in allergen sensitization between ROA and SOA were not observed. These findings contrast with those of BARR et al. [11], who documented a significantly greater number of ROA cases after exposure to respiratory allergens (dust, pets, pollen). This study applied stricter criteria for establishing allergen inhalation (absence of another possible trigger and a positive skin-prick test for the suspected allergen) than those employed by BARR et al. [11] (suspicion referred to by the patient when asked), which may explain the difference.

The observation of more crises in spring and winter as opposed to autumn, when Spain usually experiences more hospital admissions for asthma overall, supports the idea that certain allergens may play a role in fatal and near-fatal attacks [27]. Along the same lines, near-fatal asthma epidemics have been reported in spring in Australia, apparently due to exposure to allergens after storms [28]. However, the high percentage $(51 \%)$ of patients for whom the authors were unable to establish any specific trigger must be kept in mind, as must the lack of significant differences in seasonal patterns for ROA and SOA in this study. Therefore, it can be concluded that other factors, such as weather, are more likely to explain these data than allergen exposure. Finally, inhalation of fumes and irritants was a fairly common trigger of ROA $(9 \%$ of cases) in this study, as was also found by BARR et al. [11] and reported in a discussion of one case [29]. The mechanism by which fume inhalation could lead to ROA might involve direct injury of the bronchial mucosa, leading to severe bronchoconstriction rather than inflammation.

The serious deficiencies in the management of asthma that have been reported $[30,31]$ are confirmed by these data. Approximately one-half of the patients in the sample were being treated regularly by a specialist or were receiving inhaled steroid treatment. Moreover, compliance with therapy was suspected to be low among the survivors in spite of the severity of the asthma crises they experienced, given that 24 patients $(11 \%)$ failed to appear for the first follow-up visit scheduled after hospital release.

Because this study was conceived to establish the frequency and distinguishing clinical features of ROA, data cannot be provided regarding prevalence, and it may be that the percentages reported for triggers are not precise for the Spanish population overall. However, a strength of this study is that it presents the largest cohort of patients to date with ROA fatal and near-fatal attacks, with data collected prospectively according to strict criteria.

To conclude, it was found that $20 \%$ of patients with fatal or near-fatal asthma attacks experienced onset within $2 \mathrm{~h}$. Since trigger factors, clinical course and prognosis in these patients seemed to differ from those of patients with slow-onset asthma fatal or near-fatal attacks, it can be speculated that rapid-onset asthma fatal and near-fatal crises have a particular pathogenesis and ought to be managed differently from more gradually developing attacks. A clearer identification of triggers would help to establish specific preventive plans for patients at risk of rapid-onset.

Acknowledgements. The authors wish to thank T. Puig and J. Belda, both of Hospital de la Santa Creu i Sant Pau de Barcelona for their helpful comments. They also thank M.E. Kerans and C. Newey for assistance with the manuscript.

The High Risk Asthma Research Group. J. Abal, J. Ancochea, J. Armengol, S. Bardagí, J. Barrio, J.M. Benítez, J. Botey, E. Chacón, N. Cobos, F.J. Cosano, A. de Diego, A. Escribano, J.B. Gáldiz, G. García-Hernandez, I. González-M, E.G. Perez-Yarza, J.L. Heredia, J. Izquierdo, J. Korta, A. López-Viña, P. Martin Escribano, J.J. Martin-Villasclaras, E. Martínez-Moragón, R. Melchor, J.M. Merino, J. de Pablo, M. Perpiñá, C. Pellicer, C. Planell, J. Ramos, R. Sánchez-Gil, J. Serra and B. Sureda. Scientific Committee: S. Bardagí, A. de Diego, E. González-PY, A. López-Viña, J. de Pablo, C. Picado, V. Plaza, J. Sanchis and J. Serrano.

\section{References}

1. British Thoracic Association. Deaths from asthma in two regions in England. BMJ 1982; 285: 1251-1255.

2. Burney P. Asthma deaths in England and Wales 1931-85: evidence for a true increase in asthma mortality. J Epidemiol Community Health 1988; 42: 316-320.

3. Rea HH, Scragg R, Jackson R, Beaglehole R, Fenwick J, Sutherland D. A case-control study of deaths from asthma. Thorax 1986; 41: 833-839.

4. Wasserfallen JB, Schaller MD, Feihl F, Perret CH. Sudden asphyxic asthma: a distinct entity? Am Rev Respir Dis 1990; 142: 108-111.

5. Picado C. Classification of severe asthma exacerbations: a proposal. Eur Respir J 1996; 9: 1775-1778.

6. Sur S, Crotty TB, Kephart GM, et al. Sudden-onset fatal asthma: a distinct entity with few eosinophils and relatively more neutrophils in the airway submucosa? Am Rev Respir Dis 1993; 148: 713-719.

7. Faul JL, Tormey VJ, Leonard C, et al. Lung immunopathology in cases of sudden asthma death. Eur Respir J 1997; 10: 301-307.

8. Saetta M, Thiene G, Crescioli S, Fabbri LM. Fatal asthma in a young patient with severe bronchial hyperresponsiveness but stable peak flow records. Eur Respir J 1989; 2: 1008-1012.

9. Robin ED, Lewinston N. Unexpected, unexplained sudden death in young asthmatic subjects. Chest 1989; 96: 790-793

10. Kallenbach JM, Frankel AH, Lapinsky SE, et al. Determinants of near fatality in acute severe asthma. Am J Med 1993; 95: 265-272.

11. Barr RG, Woodruff PG, Clark S, et al. Sudden-onset asthma exacerbations: clinical features, response to therapy, and 2-week follow-up. Eur Respir $J$ 2000; 15 : 266-273. 
12. Rodrigo GJ, Rodrigo C. Rapid-onset asthma attack. A prospective cohort study about characteristics and response to emergency department treatment. Chest 2000; 118: 1547-1552.

13. Kolbe J, Fergusson W, Garrett J. Rapid onset asthma: a severe but uncommon manifestation. Thorax 1998; 53: $241-247$.

14. Ryan G, Musk AW, Perera DM, Stock H, Knight JL, Hobbs MST. Risk factors for death in patients admitted to hospital with asthma: a follow-up study. Aust NZ J Med 1991; 21: 681-685.

15. Turner MO, Noertjojo K, Vedal S, Bai T, Crump S, Fitzgerald JM. Risk factors for near-fatal asthma. A case-control study in hospitalized patients with asthma. Am J Respir Crit Care Med 1998; 157: 1804 1809.

16. American Thoracic Society. Standards for the diagnosis and care of patients with chronic obstructive pulmonary disease (COPD) and asthma. Am Rev Respir Dis 1987; 136: 225-244.

17. Carroll N, Carello S, Cooke C, James A. Airway structure and inflammatory cells in fatal attacks of asthma. Eur Respir J 1996; 9: 709-715.

18. National Institutes of Health, National Heart, Lung and Blood Institute. Global Initiative for Asthma. Global Strategy for Asthma Management and Prevention. National Heart, Lung, and Blood Institute/ World Health Organization Workshop Report. Publication No. 95-3659. Bethesda, MD, USA, National Institutes of Health/World Health Organization, 1995.

19. American Thoracic Society. Official Statement. Standardization of spirometry. 1994 Update. Am J Respir Crit Care Med 1994; 152: 1107-1136.

20. Netherlands Society of Allergology, Committee on Skin Test Standardization. Report on skin test standardization. Clin Allergy 1988; 18: 305-310.

21. Sears MR, Rea HH, Beaglehole R, et al. Asthma mortality in New Zealand: a two year national study. NZ Med J 1985; 98: 271-275.

22. Picado C, Castillo JA, Montserrat JM, Agusti Vidal A. Aspirin-intolerance as a precipitating factor of lifethreatening attacks of asthma requiring mechanical ventilation. Eur Respir J 1989; 2: 127-129.

23. Matsuse H, Shimoda T, Matsuo N, et al. Aspirininduced asthma as a risk factor for asthma mortality. J Asthma 1997; 34: 413-417.

24. Poulter LW, Faul J, O'Sullivan S. Cytotoxic T cell response associated with sudden asphyxic asthma death. Am J Respir Crit Care Med 2000; 161s: A926.

25. Woodruff PG, Emond SD, Singh AK, Camargo CA Jr. Sudden-onset severe acute asthma: clinical features and response to therapy. Acad Emerg Med 1998; 5: 695-701.

26. Antó JM, Sunyer J, Rodriguez-Roisin R, et al. Community outbreaks of asthma associated with inhalation of soybean dust. N Engl J Med 1989; 320: 1097-1102.

27. Serrano J, Plaza V, Sanchis J. Ingreso en el hospital por asma. Análisis descriptivo y factores pronósticos tras el alta. Arch Bronconeumol 1999; 35: 372-378.

28. Bellomo R, Gigliotti P, Treolar A, et al. Two consecutive thunderstorm associated epidemics of asthma in the city of Melbourne. Med J Aust 1992; 156: 834-837.

29. Huber AL, Loving TJ. Fatal asthma attack after inhaling sulfur fumes. JAMA 1991; 266: 2225.

30. Dales RE, Schweitzer I, Kerr P, Gougeon L, Rivington R, Draper J. Risk factors for recurrent emergency department visits for asthma. Thorax 1995; 50: $520-524$.

31. Hartet TV, Windom HH, Peebles RS, Freidhoff LR, Togias A. Inadequate outpatient medical therapy for patients with asthma admitted to two urban hospitals. Am J Med 1996; 100: 386-394. 